\title{
MASKING TETRACYCLINE STAINED TEETH: EFFECT OF TRANSLUCENCY AND THICKNESS OF MULTIPLE CAD-CAM VENEER MATERIALS AND SHADES OF RESIN CEMENTS
}

\author{
Mona M. Ghoneim* and Doaa R M Ahmed*
}

\begin{abstract}
This study aimed to assess the masking potential of different CAD-CAM veneer restorations to restore tetracycline-stained teeth. One-hundred-eight CAD-CAM ceramic discs, shade 1M1, with high (HT) and low (LT) translucencies and $1 \mathrm{~mm}$ and $0.7 \mathrm{~mm}$ thicknesses were prepared from three CAD-CAM materials (IPS-e.max-CAD (EMC), VITA Enamic (VE) and Vita Suprinity (VS)). Resin cements, shades A1, white opaque (WO) and translucent (T), were used for cementation against a dark base. Color differences $\left(\Delta \mathrm{E}^{*}\right)$ between the restorations (veneer/resin cement/dark base) and a standard 1M1 shade-guide-tab were calculated. Mann-Whitney-U and Wilcoxon-signed-rank tests; and one-way ANOVA, Kruskal-Wallis and Bonferroni-post-hoc tests were used to compare between two and three groups respectively ( $\mathrm{P} \leq 0.05$ ). Groups EMC-LT-0.7-T, VE-LT-1-A1 and VE-LT-1-T rendered restorations with $\Delta \mathrm{E}^{*}$ below the perceptibility threshold $(<1.74)$, while EMCLT-0.7-A1 and all LT-0.7mm VE restorations were within the acceptability threshold $(<3.48)$. VS had significantly higher $\left(\Delta \mathrm{E}^{*}\right)$ compared to of EMC and VE materials. Ceramic thicknesses had no significant effect on $\left(\Delta \mathrm{E}^{*}\right)$, while the effect of translucency level of the ceramics and the shade of resin cement was significant. It was concluded that low translucency ceramic veneers can better mask darkly stained teeth, irrespective of their thicknesses, with resin cements shades affecting the color of the final restorations.
\end{abstract}

Key words: CAD-CAM, dental veneers, tetracycline-staining, resin cements, translucency

\section{INTRODUCTION}

Dental esthetics, and teeth color in particular, has recently become a social concern for many, for its influence on general appearance and selfconfidence ${ }^{(1)}$. Tooth discoloration varies in severity and in types, whether extrinsic or intrinsic, the latter being more difficult to treat with non-invasive procedures such as prophylaxis and bleaching ${ }^{(2)}$. Of the most challenging tooth discoloration, are the ones caused by tetracycline antibiotic treatment ${ }^{(3)}$.

Since their discovery in the 1940s, tetracyclines have been used intensively for the prophylaxis and

\footnotetext{
* Associate Professor Conservative Dentistry Department, Faculty of Dentistry, Alexandria University, Egypt.
} 
treatment of variable infections ${ }^{(4)}$. Nevertheless, despite their success as being an affordable broadspectrum antibiotic, and the drug of choice for the treatment of acne vulgaris ${ }^{(5)}$, tetracyclines present several adverse effects $^{(6)}$. When systemically administered during the period of tooth formation, or when used during root canal treatment as an intracanal medication or irrigants, tetracycline readily binds to both tooth enamel and dentin by chelating to calcium ions, with the resulting formation of tetracycline-calcium orthophosphate complexes. Upon light exposure, these complexes oxidize leading to the formation of varying degrees of yellow or brown-grey permanent tooth discoloration. The hue of the tooth discoloration has mainly been linked to the type of the tetracycline derivative, while the intensity is mainly dependent on the dosage and the duration of the treatment ${ }^{(7)}$.

Micro-abrasion and bleaching procedures have been used to improve tetracycline induced tooth discoloration, but their success is limited to superficial and light yellowish discoloration ${ }^{(2)}$. For darker tooth discoloration, laminate veneers are regarded as the optimum conservative treatment modality ${ }^{(3)}$.

Of the different types of laminate veneers, CADCAM fabricated veneers have recently gained popularity, offering the use of a variety of material compositions. Three main categories of monolithic CAD-CAM blocks can be identified: glass, polycrystalline and the resin-matrix ceramics ${ }^{(8)}$. Of the glass ceramics category, lithium disilicate has been recognized for offering highly esthetic restorations with good physical properties, yet its use is not recommended in high stress-bearing areas ${ }^{(9,10)}$.

Polycrystalline ceramics have thus been introduced to the market to present a material with higher mechanical properties. These materials comprise of yttria-stabilized tetragonal zirconia, offering higher mechanical properties and fracture toughness by interruption of crack propagation but have compromised translucency. In order to take advantage of their mechanical properties, a class of material has been developed, composed of glass (lithium silicate) that is reinforced with a polycrystalline phase. These zirconia reinforced lithium silicate materials are thought to take advantage of both glass ceramics and zirconia ${ }^{(11)}$. The glassy matrix contains zirconia which reinforces the ceramic structure by acting as nucleating agent thus providing crack interruption, as well as very fine lithium metasilicate and lithium disilicate crystals that have been shown to enhance the material's translucency ${ }^{(12,13)}$.

In parallel, another category of CAD-CAM materials was developed to take advantage of ceramics and resin material. These resin matrix ceramics or so-called hybrid ceramics consist of a fine structured feldspathic ceramic network infiltrated by a polymer resin and show advantages such as having adequate esthetic properties, an elastic modulus closer to that of dentin and being easier to mill and readily repaired intraorally ${ }^{(14)}$.

Nevertheless, when dealing with severely discolored teeth such as tetracycline stained teeth, the masking ability of the restoration is not only dependent of the type of veneer material that inherently affect its translucency but other factors, such as the veneer thickness and the optical properties of the luting resin cement, may play an important role in the final esthetic appearance of the restoration ${ }^{(2,15)}$. Thus, the aim of the current study was to assess the masking potential of different CAD-CAM veneer materials, having different translucency levels and thicknesses in combination with different shades of resin luting cements in order to reach a restoration of shade $1 \mathrm{M} 1$ (according to Vita 3D Master shade guide). The null hypotheses were:1/ none of the veneer restorations tested will be able to mask the underlying stained base color, 2/ veneer material composition, translucency level and thickness will not affect the masking ability of the veneer, $3 /$ resin cement shade will not affect the masking ability of the veneer restoration. 


\section{MATERIALS AND METHODS}

\section{Materials Tested}

A total of one hundred and eight CAD-CAM ceramic discs were prepared from 3 different CADCAM material blocks (a glass ceramic - IPS-e. max-CAD (EMC), a hybrid ceramic -VITA Enamic (VE) and a zirconia reinforced glass ceramic Vita Suprinity (VS)). 1M1 shade or its equivalent was chosen for all materials with two different translucencies (high translucency - HT and low translucency - T). The CAD-CAM ceramics and resin cement materials' properties and manufacturers are listed in table 1.

Specimens with $1 \pm 0.05$ - $\mathrm{mm}$ and $0.7 \pm 0.05-\mathrm{mm}$ thicknesses were prepared from each CAD-CAM veneer material using a water cooled low-speed diamond saw (Isomet; Buehler, Lake Bluff, IL). EMC specimens were subjected to a crystallization cycle for $10 \mathrm{~min}$ at $850^{\circ} \mathrm{C}$ in their respective oven (ProgramatEP5000; Ivoclar Vivadent AG) according to the manufacturer's instructions. Specimen thickness was confirmed by a digital micrometer (Mastercraft, electronic caliper, Canadian Tire Corporation, Ltd, Canada) to $0.05 \mathrm{~mm}$ accuracy.

\section{Measuring Color Parameters of the CAD-CAM Specimens}

After CAD-CAM specimen preparation, and before application of the resin cement, the color parameters of specimens were measured using the Easyshade Advance spectrophotometer (Vita Zahnfabrik, Germany). The spectrophotometer displayed the different color parameters $\left(\mathrm{L}^{*}, \mathrm{a}^{*}\right.$ and $\left.b^{*}\right)$ according to the CIELab color system, where $\mathrm{L}^{*}$ describes the luminance reflectance, whereas $\mathrm{a}^{*}$ and $\mathrm{b}^{*}$ describe the red-green and yellow-blue color coordinates, respectively. Specimen color was initially measured against a standard white and against a dark orange-brown ceramic tiles with measured color coordinates of $\mathrm{L}_{\mathrm{w}}=83.1$, $\mathrm{a}_{\mathrm{w}}=0.2, \mathrm{~b}_{\mathrm{w}}=15.2$ and $\mathrm{L}_{\mathrm{d}}=70.4, \mathrm{a}_{\mathrm{d}}=7.9$ and $\mathrm{b}_{\mathrm{d}}=28.3$ respectively. The ceramic tile color was chosen to fit within the range reported for tetracycline

TABLE (1) Materials used in the study

\begin{tabular}{|c|c|c|c|c|c|c|}
\hline & Classification & Brand Name & Shades & Composition* & Code & Manufacturer \\
\hline \multirow{3}{*}{$\mid$} & $\begin{array}{l}\text { Lithium Disilicate } \\
\text { Glass Ceramic }\end{array}$ & IPS-e.max-CAD & $\begin{array}{l}\text { A1-LT } \\
\text { A1-HT }\end{array}$ & 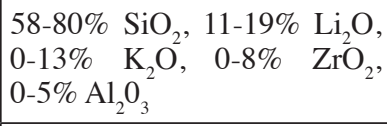 & EMC & $\begin{array}{l}\text { Ivoclar Vivadent } \\
\text { (Schaan, } \\
\text { Liechtenstein) }\end{array}$ \\
\hline & Hybrid Ceramic & Vita Enamic & $\begin{array}{c}\text { 1M1-T } \\
\text { 1M1-HT }\end{array}$ & $\begin{array}{l}-86 \% \text { ceramic }(58-63 \% \\
\quad \mathrm{SiO}_{2}, 20-23 \% \mathrm{Al}_{2} \mathrm{O}_{3}, \\
9-11 \% \mathrm{Na}_{2} \mathrm{O}, 4-6 \% \mathrm{~K}_{2} \mathrm{O}, \\
\left.0-1 \% \mathrm{ZrO}_{2}\right) \\
- \\
\text { - } 14 \% \text { polymer (UDMA, } \\
\text { TEGDMA) }\end{array}$ & VE & $\begin{array}{l}\text { VITA Zahnfabrik } \\
\text { (Schaan, } \\
\text { Liechtenstein) }\end{array}$ \\
\hline & $\begin{array}{c}\text { Zirconia } \\
\text { Reinforced Glass } \\
\text { Ceramic }\end{array}$ & Vita Suprinity & $\begin{array}{l}\text { 1M1-T } \\
1 \mathrm{M} 1-\mathrm{HT}\end{array}$ & $\begin{array}{l}56-64 \% \mathrm{SiO}_{2}, 1-4 \% \mathrm{Al}_{2} 0_{2} \\
15-21 \% \mathrm{Li}_{2} \mathrm{O}, 8-12 \% \mathrm{ZrO}^{2} \\
1-4 \% \mathrm{~K}_{2} \mathrm{O}\end{array}$ & VS & $\begin{array}{l}\text { VITA Zahnfabrik } \\
\text { (Schaan, } \\
\text { Liechtenstein) }\end{array}$ \\
\hline . & $\begin{array}{c}\text { Light Cure Resin } \\
\text { Cement }\end{array}$ & Rely X veneer & $\begin{array}{l}\text { A1, light yellow } \\
\text { T, Translucent } \\
\text { WO, White } \\
\text { Opaque }\end{array}$ & $\begin{array}{l}\text { - } \text { BisGMA, TEGDMA } \\
\text { polymer. } \\
\text { - } 66 \% \text { by weight Zirconia/ } \\
\text { silica and fumed silica } \\
\text { fillers }\end{array}$ & RXV & $\begin{array}{l}\text { 3M ESPE } \\
\text { (St. Paul, MN, USA) }\end{array}$ \\
\hline
\end{tabular}

*As disclosed by manufacturers Abbreviations: $\mathrm{SiO}_{2}$ : Silicon dioxide, $\mathrm{Li}_{2} \mathrm{O}$ : Lithium oxide, $\mathrm{K}_{2} \mathrm{O}:$ Potassium oxide, $\mathrm{ZrO}_{2}$ : Zirconium dioxide, $\mathrm{Al}_{2} \mathrm{O}_{3}$ : Aluminum oxide, $\mathrm{Na}_{2} \mathrm{O}$ : Sodium oxide, UDMA: urethane dimethacrylate, TEGDMA: Triethylene glycol dimethacrylate, BisGMA: bisphenol A-glycidyl methacrylate. 
stained teeth ${ }^{(16)}$. The spectrophotometer was regularly calibrated according to the manufacturer's recommendation. Three measurements were taken three times for each specimen, and an average of the reading was calculated.

\section{Cementation of the CAD-CAM Specimens}

To prepare for cementation, all specimens were ultrasonically cleaned for 10 minutes, then the intaglio surface were treated with hydrofluoric acid (IPS Etching Gel; Ivoclar Vivadent) for 60 seconds then air-dried. A single coat of silane ceramic primer (RelyX ${ }^{\mathrm{TM}}$ Ceramic Primer, 3M ESPE) was then applied to the etched surface and dried. One coat of adhesive was then applied to the silane treated surface of the specimen and dried gently for 5 seconds before applying the assigned shade of RelyX Veneer Cement to the veneer specimen. The veneer specimens were then gently seated over the tile squares. In order to standardize resin cement thickness during all cementation procedures to $0.1 \mathrm{~mm}$ thickness ${ }^{(15,17)}, 2$ layers of stainless-steel metal matrix bands $(0.1 \mathrm{~mm}$ thickness in total) were secured over the ceramic tiles (figure 1) to hold the edges of the veneer specimens before seating of veneer specimens. Clinical conditions were simulated by applying $9.8 \mathrm{~N}$ force to the ceramic surface for 20 seconds, then light polymerization was performed using an LED curing light (Elipar Freelight 2; 3M ESPE) for 40 seconds. Three different resin cement shades (A1, white opaque (WO) and translucent (T)) were used for cementation of the different ceramic specimens. Excess cement was then removed, and the margins cleaned up. The study design and the grouping are shown in table 2 .

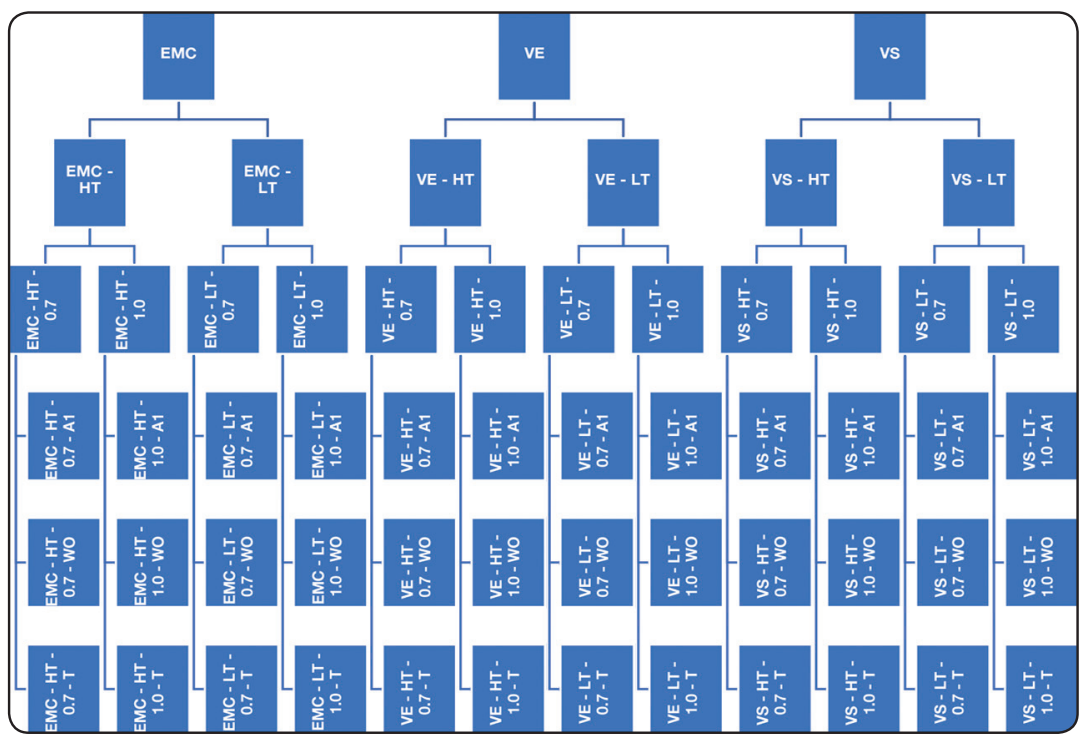

Fig. (1) Study design and grouping : Abbreviations: EMC: IPS-e.maxCAD; VE: Vita Enamic; VS: Vita Suprinity; HT: High translucency ceramic material; LT: low translucency ceramic material; 0.7: $0.7 \mathrm{~mm}$ thickness of ceramic specimen; $1: 1 \mathrm{~mm}$ thickness of ceramic specimen; $\mathrm{T}$ : Translucent resin cement shade, WO: white opaque resin cement shade, A1: A1 resin cement shade.

TABLE (2) Comparison of the color coordinates of the different ceramic materials on a standard white base

\begin{tabular}{|l|c|c|c|c|}
\hline \multirow{2}{*}{} & \multicolumn{3}{|c|}{ Mean \pm SD } & \multirow{2}{*}{$\begin{array}{c}\text { P Value } \\
\text { One-Way ANOVA }\end{array}$} \\
\cline { 2 - 4 } & $\mathbf{E M C}(\mathbf{n}=\mathbf{3 6})$ & $\mathbf{V E}(\mathbf{n}=\mathbf{3 6})$ & $\mathbf{V S}(\mathbf{n}=\mathbf{3 6})$ & $<0.001^{*}$ \\
\hline $\mathbf{L}^{*}$ & $95.18 \pm 1.33^{a}$ & $96.85 \pm 1.80^{b}$ & $87.65 \pm 2.21^{c}$ & $<0.001^{*}$ \\
\hline $\mathbf{b}^{*}$ & $-1.68 \pm 0.43^{a}$ & $-0.48 \pm 0.58^{b}$ & $-1.33 \pm 0.21^{c}$ & $<0.001^{*}$ \\
\hline
\end{tabular}

*statistically significant at p value $\leq 0.05$ Different superscripts denote statistically significant difference between groups using Bonferroni adjustment for multiple comparisons. 
Measuring color parameters of the cemented CAD-CAM restoration against the dark base

In order to assess the masking ability of the different restorations, color difference $\left(\Delta \mathrm{E}^{*}\right)$ between the restoration (veneer + resin cement + dark base) and a standard 1M1 3D master shade guide tab was calculated according to the following equation:

$\Delta \mathrm{E}^{*}=\left[\left(\mathrm{L}_{1}-\mathrm{L}_{2}\right)^{2}+\left(\mathrm{a}_{1}-\mathrm{a}_{2}\right)^{2}+\left(\mathrm{b}_{1}-\mathrm{b}_{2}\right)^{2}\right]^{1 / 2}$, where $\mathrm{L}_{1}=\mathrm{L}_{\text {of final restoration }}, \mathrm{L}_{2}=\mathrm{L}_{\text {of standard 1M1 shade tab }}, \mathrm{a}_{1}=\mathrm{a}_{\text {of }}$ final restoration, $\mathrm{a}_{2}=\mathrm{a}$ of standard $1 \mathrm{M} 1$ shade tab, $\mathrm{b}_{1}=\mathrm{b}_{\text {of final restoration? }}$, $\mathrm{b}_{2}=\mathrm{b}_{\text {of standard } 1 \mathrm{M} 1 \text { shade tab }}$.

The 1M1 shade guide tab color coordinates measured by the spectrophotometer were $\mathrm{L}_{2}=83.1$, $\mathrm{a}_{2}=0.2$ and $\mathrm{b}_{2}=15.2$.

The difference in color between the restorations and ceramic specimens without cementation against a dark base were also assessed using the same equation.

$\Delta \mathrm{E}_{(\mathrm{d})}^{*}=\left[\left(\mathrm{L}_{1}-\mathrm{L}_{\mathrm{d}}\right)^{2}+\left(\mathrm{a}_{1}-\mathrm{a}_{\mathrm{d}}\right)^{2}+\left(\mathrm{b}_{1}-\mathrm{b}_{\mathrm{d}}\right)^{2}\right]^{1 / 2}$, where the subscripts (d) indicates the color coordinates of the ceramic specimens, without resin cementation, measured against a dark base.

In order to evaluate the color difference values obtained in the study, the 50:50\% acceptability threshold value (AT) of 3.48 and 50:50 \% perceptibility threshold value (PT) of 1.74 determined by GHINEA et al(18), using TSK Fuzzy Approximation, were taken as reference.

\section{Statistical Analysis}

Normality was checked for all variables using histograms, boxplots and normality tests. Means and standard deviations were calculated for all variables. Comparison of three groups was done using One Way ANOVA (different veneers on a white base) when the variable showed normal distribution and using Kruskal- Wallis test (different veneer materials and resin cement shades) when the variable was not normally distributed. Both tests were followed by Bonferroni post hoc test for multiple pairwise comparisons using Bonferroni adjustment. Comparing two groups (different translucencies and thicknesses of the veneers) was done using Mann-Whitney U test. Comparison of the color of the same specimens with and without resin cement was done using Wilcoxon signed rank test. Univariate linear regression analysis was done incl uding all variables, one at a time, as explanatory variables, followed by multivariable regression analysis to determine the effect of different factors on the color of the final restoration. Significance was set at $\mathrm{P} \leq 0.05$. Data was analyzed using IBM SPSS statistical software (version 25).

\section{RESULTS}

Color measurement of the different ceramic specimens, prior to cementation, against a white background, indicated there was a significant difference between the color coordinates amongst the three ceramic materials. Only for the $b^{*}$ coordinate, there was no significant difference between the EMC and VE materials (table 2).

Means and standard deviations of $\mathrm{L}^{*}, \mathrm{a}^{*}$, and $b^{*}$ coordinates of the cemented specimens against the dark base, and $\Delta \mathrm{E}^{*}$ values in comparison to a standard 1M1 3D master shade guide tab are presented in Table 3. Groups EMC-LT-0.7-T, VELT-1-A and VE-LT-1-T rendered restorations with color difference from 1M1 shade that are below the perceptibility threshold (Delta E values of 1.51, 1.23 and 1.36 respectively). EMC-LT-0.7-A1 and VE restorations in low translucency and $0.7 \mathrm{~mm}$ thickness cemented with the three shades of resin cements tested, rendered restoration shades within the acceptability threshold ( $\Delta \mathrm{E}^{*}$ values of $2.21,3.08$, 3.31 and 2.41 respectively). All other restorations tested rendered a difference in color compared to a standard 1M1 shade guide tab that are clinically unacceptable.

Kruskal -Wallis Test comparing the color 
TABLE (3) Mean and standard deviation of color coordinates and color difference $\left(\Delta \mathrm{E}^{*}\right)$ of the different restorations compared to a standard 1M1 3D Master shade Guide

\begin{tabular}{|c|c|c|c|c|}
\hline Groups & $\begin{array}{c}\mathrm{L}^{*} \\
(\mathrm{mean} \pm \mathrm{SD})\end{array}$ & $\begin{array}{c}\mathbf{a}^{*} \\
(\text { mean } \pm \text { SD })\end{array}$ & $\begin{array}{c}\mathbf{b}^{*} \\
(\text { mean } \pm \text { SD })\end{array}$ & $\begin{array}{c}\left(\Delta \mathrm{E}^{*}\right) \\
(\operatorname{mean} \pm \mathrm{SD})\end{array}$ \\
\hline EMC-HT-0.7-A1 & $71.30 \pm 0.46$ & $-0.33 \pm 0.06$ & $2.77 \pm 0.06$ & $17.12 \pm 0.26$ \\
\hline EMC-HT-0.7-WO & $76.23 \pm 0.42$ & $-0.90 \pm 0.00$ & $0.97 \pm 0.15$ & $15.80 \pm 0.31$ \\
\hline EMC-HT-0.7-T & $65.03 \pm 0.9$ & $-0.10 \pm 0.00$ & $1.60 \pm 0.17$ & $22.57 \pm 0.82$ \\
\hline EMC-HT-1-A1 & $69.43 \pm 0.49$ & $-0.50 \pm 0.00$ & $3.67 \pm 0.15$ & $17.85 \pm 0.45$ \\
\hline EMC-HT-1-WO & $83.5 \pm 0.17$ & $-2.27 \pm 0.15$ & $2.50 \pm 0.20$ & $12.91 \pm 0.22$ \\
\hline EMC-HT-1-T & $64.70 \pm 1.23$ & $-0.53 \pm 0.06$ & $2.30 \pm 0.26$ & $22.44 \pm 1.15$ \\
\hline VE-HT-0.7-A1 & $57.60 \pm 0.00$ & $0.90 \pm 0.00$ & $6.13 \pm 0.06$ & $27.03 \pm 0.02$ \\
\hline VE-HT-0.7-WO & $77.67 \pm 1.50$ & $0.17 \pm 0.12$ & $6.60 \pm 0.35$ & $10.17 \pm 1.06$ \\
\hline VE-HT-0.7-T & $77.30 \pm 0.10$ & $0.60 \pm 0.00$ & $9.40 \pm 0.20$ & $8.17 \pm 0.21$ \\
\hline VE-HT-1-A1 & $65.30 \pm 0.10$ & $0.00 \pm 0.00$ & $6.73 \pm 0.12$ & $19.67 \pm 0.10$ \\
\hline VE-HT-1-WO & $70.73 \pm 0.31$ & $-0.80 \pm 0.10$ & $3.50 \pm 0.26$ & $17.01 \pm 0.22$ \\
\hline VE-HT-1-T & $74.77 \pm 0.93$ & $-0.10 \pm 0.00$ & $8.83 \pm 0.35$ & $10.45 \pm 0.95$ \\
\hline VS-HT-0.7-A1 & $48.13 \pm 0.15$ & $6.97 \pm 0.12$ & $19.70 \pm 0.53$ & $35.88 \pm 0.20$ \\
\hline VS-HT-0.7-WO & $57.67 \pm 0.15$ & $3.30 \pm 0.40$ & $8.47 \pm 1.40$ & $26.48 \pm 0.36$ \\
\hline VS-HT-0.7-T & $60.20 \pm 0.17$ & $4.30 \pm 0.26$ & $11.17 \pm 0.49$ & $23.58 \pm 0.14$ \\
\hline VS-HT-1-A1 & $59.73 \pm 0.25$ & $4.60 \pm 0.00$ & $15.47 \pm 0.32$ & $23.76 \pm 0.25$ \\
\hline VS-HT-1-WO & $59.13 \pm 0.29$ & $3.13 \pm 0.06$ & $10.17 \pm 0.15$ & $24.63 \pm 0.30$ \\
\hline VS-HT-1-T & $61.77 \pm 0.50$ & $3.03 \pm 0.12$ & $10.57 \pm 0.12$ & $21.98 \pm 0.50$ \\
\hline EMC-LT-0.7-A1 & $84.40 \pm 0.26$ & $-0.93 \pm 0.06$ & $16.53 \pm 0.15$ & $2.21 \pm 0.19$ \\
\hline EMC-LT-0.7-WO & $91.20 \pm 0.20$ & $-1.60 \pm 0.10$ & $17.43 \pm 0.38$ & $8.63 \pm 0.13$ \\
\hline EMC-LT-0.7-T & $83.57 \pm 0.32$ & $-0.70 \pm 0.00$ & $16.27 \pm 0.12$ & $1.51 \pm 0.14$ \\
\hline EMC-LT-1-A1 & $85.50 \pm 0.26$ & $-0.42 \pm 0.31$ & $18.17 \pm 0.12$ & $3.92 \pm 0.16$ \\
\hline EMC-LT-1-WO & $87.43 \pm 0.15$ & $-1.37 \pm 0.06$ & $17.47 \pm 0.38$ & $5.17 \pm 0.28$ \\
\hline EMC-LT-1-T & $85.67 \pm 0.15$ & $-0.60 \pm 0.00$ & $17.90 \pm 0.20$ & $3.85 \pm 0.22$ \\
\hline VE-LT-0.7-A1 & $80.17 \pm 0.23$ & $0.77 \pm 0.06$ & $14.37 \pm 0.35$ & $3.08 \pm 0.17$ \\
\hline VE-LT-0.7-WO & $85.60 \pm 0.36$ & $0.63 \pm 0.06$ & $13.10 \pm 0.00$ & $3.31 \pm 0.27$ \\
\hline VE-LT-0.7-T & $81.50 \pm 0.10$ & $1.10 \pm 0.00$ & $13.60 \pm 0.17$ & $2.41 \pm 0.14$ \\
\hline VE-LT-1-A1 & $82.10 \pm 0.10$ & $0.87 \pm 0.06$ & $15.43 \pm 0.06$ & $1.23 \pm 0.08$ \\
\hline VE-LT-1-WO & $88.37 \pm 0.06$ & $0.13 \pm 0.06$ & $14.93 \pm 0.29$ & $5.31 \pm 0.04$ \\
\hline VE-LT-1-T & $82.47 \pm 0.06$ & $0.70 \pm 0.00$ & $14.07 \pm 0.06$ & $1.36 \pm 0.04$ \\
\hline VS-LT-0.7-A1 & $60.80 \pm 0.20$ & $3.27 \pm 0.32$ & $13.07 \pm 0.76$ & $22.59 \pm 0.22$ \\
\hline VS-LT-0.7-WO & $62.37 \pm 0.31$ & $2.27 \pm 0.06$ & $8.10 \pm 0.10$ & $21.97 \pm 0.32$ \\
\hline VS-LT-0.7-T & $61.50 \pm 0.40$ & $3.63 \pm 0.12$ & $11.77 \pm 0.31$ & $22.11 \pm 0.42$ \\
\hline VS-LT-1-A1 & $60.10 \pm 0.53$ & $2.77 \pm 0.21$ & $11.53 \pm 0.23$ & $23.40 \pm 0.51$ \\
\hline VS-LT-1-WO & $60.37 \pm 0.38$ & $2.60 \pm 0.50$ & $7.93 \pm 1.06$ & $23.97 \pm 0.61$ \\
\hline VS-LT-1-T & $56.27 \pm 0.31$ & $3.87 \pm 0.12$ & $12.47 \pm 0.67$ & $27.19 \pm 0.34$ \\
\hline
\end{tabular}


difference of the restorations made with the three types of ceramic materials tested to a standard $1 \mathrm{~m} 1$ Shade guide tab revealed that restorations made of VS material had a significantly higher color difference compared to those made of EMC and VE materials, with no significant difference between the latter two (figure 2). Color differences were mainly due high variations in $\mathrm{L}^{*}$ and $\mathrm{a}^{*}$ coordinates while no significant difference was noted in the $b^{*}$ coordinates (table 4).

TABLE (4) Mean and standard deviation (mean \pm SD) of color coordinates and color difference $\left(\Delta \mathrm{E}^{*}\right)$ of the final restorations made of different ceramic materials in comparison to the standard $1 \mathrm{M} 1$ shade guide tab

\begin{tabular}{|l|c|c|c|c|}
\hline & \multicolumn{3}{|c|}{ Mean \pm SD } & \multirow{2}{*}{$\begin{array}{l}\text { P Value } \\
\text { (KWT) }\end{array}$} \\
\cline { 2 - 5 } & EMC (n=36) & VE $(\mathbf{n = 3 6})$ & VS (n=36) & \\
\hline $\mathbf{L}^{*}$ & $79.01 \pm 8.97^{a}$ & $76.96 \pm 8.53^{a}$ & $59.00 \pm 3.72^{b}$ & $<0.001^{*}$ \\
\hline $\mathbf{a}^{*}$ & $-0.85 \pm 0.60^{a}$ & $0.41 \pm 0.53^{b}$ & $3.64 \pm 1.23^{c}$ & $<0.001^{*}$ \\
\hline $\mathbf{b}^{*}$ & $9.80 \pm 7.65$ & $10.56 \pm 4.03$ & $11.70 \pm 3.28$ & 0.73 \\
\hline $\mathbf{\Delta E}^{*}$ & $11.17 \pm 7.66^{a}$ & $9.10 \pm 8.03^{a}$ & $24.79 \pm 3.77^{b}$ & $<0.001^{*}$ \\
\hline
\end{tabular}

KWT: Kruskal -Wallis Test

*statistically significant at p value $\leq \mathbf{0 . 0 5}$

Different superscripts denote statistically significant difference between groups using Bonferroni adjustment for multiple comparisons.

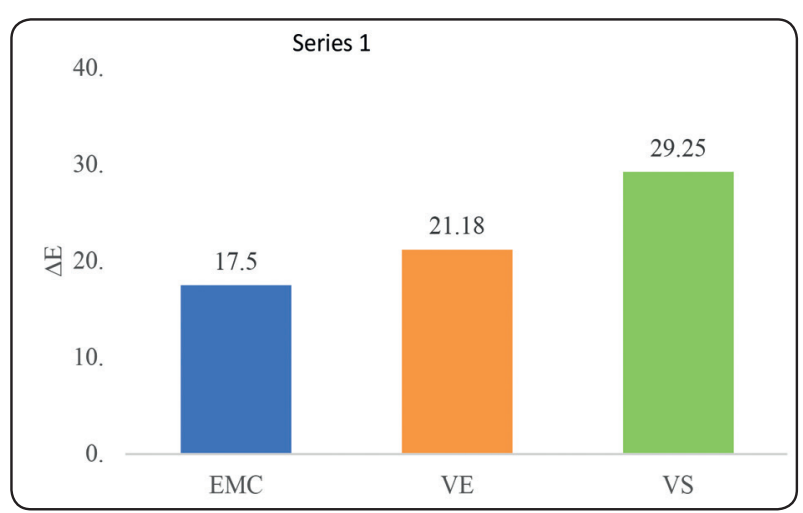

Fig. (2) Color difference $\left(\Delta \mathrm{E}^{*}\right)$ of the final restorations made of different ceramic materials in comparison to the standard 1M1 shade guide tab Abbreviations: EMC: IPS-e.max-CAD; VE: Vita Enamic; VS: Vita Suprinity
According to Mann-Whitney U Test, the ceramic thickness, whether 0.7 or $1 \mathrm{~mm}$ did not have a significant effect on the color difference compared to the standard 1M1 shade guide tab (table 5). This was true for both high and low translucency specimens (figure 2). On the other hand, the translucency level of the ceramic material did have a significant effect on the color difference compared to the standard 1M1 shade guide tab (Table 6).

TABLE (5) Mean and standard deviation (mean \pm SD) of color coordinates and color difference $\left(\Delta \mathrm{E}^{*}\right)$ of the final restorations made of different ceramic thickness in comparison to the standard $1 \mathrm{M} 1$ shade guide tab

\begin{tabular}{|l|c|c|c|}
\hline & \multicolumn{2}{|c|}{ Mean $\mathbf{\text { SD }}$} & $\begin{array}{c}\text { P Value } \\
\text { Mann-Whitney } \\
\text { U Test }\end{array}$ \\
\cline { 2 - 4 } & $\mathbf{0 . 7 m m}(\mathbf{n = 5 4})$ & $\mathbf{1 m m}(\mathbf{n = 5 4})$ & 0.68 \\
\hline $\mathbf{L}^{*}$ & $71.24 \pm 12.06$ & $72.08 \pm 11.38$ & 0.32 \\
\hline $\mathbf{a}^{*}$ & $1.30 \pm 2.20$ & $0.84 \pm 1.95$ & 0.74 \\
\hline $\mathbf{b}^{*}$ & $10.76 \pm 5.32$ & $10.61 \pm 5.42$ & 0.94 \\
\hline $\mathbf{\Delta E}^{*}$ & $14.78 \pm 9.05$ & $15.26 \pm 10.37$ & \\
\hline
\end{tabular}

TABLE (6) Mean and standard deviation (mean \pm SD) of color coordinates and color difference $\left(\Delta \mathrm{E}^{*}\right)$ of the final restorations made of different ceramic translucencies in comparison to the standard 1M1 shade guide tab

\begin{tabular}{|l|c|c|c|}
\hline \multirow{2}{*}{} & \multicolumn{2}{|c|}{ Mean \pm SD } & \multirow{2}{*}{$\begin{array}{c}\text { P Value } \\
\text { Mann-Whitney } \\
\text { U Test }\end{array}$} \\
\cline { 2 - 4 } & HT (n=54) & LT (n=54) & $<0.001^{*}$ \\
\hline $\mathbf{L}^{*}$ & $66.68 \pm 8.95$ & $76.63 \pm 12.02$ & 0.91 \\
\hline $\mathbf{a}^{*}$ & $1.19 \pm 2.39$ & $0.94 \pm 1.72$ & $<0.001^{*}$ \\
\hline $\mathbf{b}^{*}$ & $7.25 \pm 4.97$ & $14.12 \pm 3.01$ & $<0.001^{*}$ \\
\hline $\mathbf{\Delta E}^{*}$ & $19.86 \pm 6.85$ & $10.18 \pm 9.74$ & \\
\hline
\end{tabular}

*statistically significant at $p$ value $\leq 0.05$ 
When assessing the effect of the resin cement on the color of the final restorations, there was a significant difference between the color of the outer surface of the ceramic when placed on a dark background with and without cementation (table 7). When, the shade of the resin cement was evaluated as a single variable as seen in table 8 , there was no significant difference between the shades of the resin cements used. Nevertheless, when it was considered in interaction with the other factors tested, there was a significant difference with the A1 resin cement shades rendering significantly higher color differences to the 1M1 shade guide tab in comparison to the other resin shades tested. Variations in the $\mathrm{L}^{*}$ values were mainly observed. The impact of the different factors on the final color of the restoration is summarized by the multivariable analysis shown in table 9 .

TABLE (7) Mean and standard deviation (mean \pm SD) of color coordinates and color difference $\left(\Delta \mathrm{E}^{*}\right)$ of the outer surface of the ceramic specimens placed on a dark background with and without resin cementation

\begin{tabular}{|c|c|c|c|}
\hline & \multicolumn{2}{|c|}{ Mean \pm SD } & \multirow{2}{*}{$\begin{array}{c}\text { P Value } \\
\text { Wilcoxon Signed } \\
\text { Rank Test }\end{array}$} \\
\hline & $\begin{array}{c}\text { With RC } \\
(n=108)\end{array}$ & Without RC & \\
\hline $\mathbf{L}^{*}$ & $71.66 \pm 11.67$ & $74.33 \pm 9.40$ & $0.007 *$ \\
\hline$a^{*}$ & $1.07 \pm 2.08$ & $2.13 \pm 2.42$ & $<0.001 *$ \\
\hline $\mathbf{b}^{*}$ & $10.69 \pm 5.35$ & $15.77 \pm 4.62$ & $<0.001 *$ \\
\hline$\Delta \mathbf{E}^{*}$ & $15.02 \pm 9.69$ & $8.77 \pm 5.45$ & $<0.001 *$ \\
\hline
\end{tabular}

* statistically significant at p value $\leq 0.05$
TABLE (8) Mean and standard deviation (mean \pm SD) of color coordinates and color difference $\left(\Delta \mathrm{E}^{*}\right)$ of the final restorations cemented with different resin cement shades

\begin{tabular}{|l|c|c|c|c|}
\hline & \multicolumn{3}{|c|}{ Mean \pm SD } & \multirow{2}{*}{ P Value } \\
\cline { 2 - 5 } & A1 (n=36) & WO $(\mathbf{n}=36)$ & T $(\mathbf{n}=36)$ & \\
\hline \multirow{2}{*}{$\mathbf{L}^{*}$} & $68.71 \pm 11.79$ & $75.03 \pm 12.20$ & $71.23 \pm 10.37$ & 0.08 \\
\hline $\mathbf{a}^{*}$ & $1.50 \pm 2.36^{a}$ & $0.44 \pm 1.90^{b}$ & $1.27 \pm 1.85^{a}$ & $0.046^{*}$ \\
\hline $\mathbf{b}^{*}$ & $11.96 \pm 5.60$ & $9.26 \pm 5.42$ & $10.83 \pm 4.78$ & 0.07 \\
\hline$\Delta \mathbf{E}^{*}$ & $16.48 \pm 11.00$ & $14.61 \pm 8.04$ & $13.97 \pm 9.89$ & 0.63 \\
\hline
\end{tabular}

KWT: Kruskal -Wallis Test was used *statistically significant at $p$ value $\leq 0.05$. Different superscripts denote statistically significant difference between groups using Bonferroni adjustment for multiple comparisons.

TABLE (9) Multivariable analysis for the effect of different factors on the final color of the restorations in comparison to a standard $1 \mathrm{M} 1$ shade guide tab

\begin{tabular}{|c|c|c|c|}
\hline \multicolumn{2}{|c|}{ Factor } & B $(95 \%$ CI $)$ & P Value \\
\hline \multirow{3}{*}{ Ceramic Type } & EMC & $\begin{array}{c}-13.63(-15.79 \\
-11.47)\end{array}$ & $<0.001^{*}$ \\
\hline & VE & $\begin{array}{c}-15.70(-17.85 \\
-13.54)\end{array}$ & $<0.001^{*}$ \\
\hline & VS & \multicolumn{2}{|c|}{ Reference } \\
\hline \multirow{2}{*}{ Translucency } & HT & $9.68(7.92,11.44)$ & $<0.001 *$ \\
\hline & LT & \multicolumn{2}{|c|}{ Reference } \\
\hline \multirow{2}{*}{ Thickness } & $0.7 \mathrm{~mm}$ & $0.48(-1.29,2.24)$ & 0.59 \\
\hline & $1 \mathrm{~mm}$ & \multicolumn{2}{|c|}{ Reference } \\
\hline \multirow{3}{*}{ Cement Shade } & A1 & $2.51(0.35,4.67)$ & $0.02 *$ \\
\hline & WO & $0.64(-1.51,2.80)$ & 0.56 \\
\hline & $\mathbf{T}$ & \multicolumn{2}{|l|}{ Reference } \\
\hline
\end{tabular}

B: Regression coefficient

CI: Confidence interval

*statistically significant at $\mathrm{p}$ value $\leq 0.05$

Adjusted $\mathrm{R}^{2}=0.77, \mathrm{~F}=61.83, \mathrm{P}$ value $<0.001 *$ 


\section{DISCUSSION}

Technological advances in CAD-CAM materials and adhesive cementation of restorations have opened an array of solutions for dental treatment in the esthetic zone. One of the most commonly advocated restorations, are the laminate veneers, offering conservative treatment modalities for discolored teeth, when other minimally invasive procedures are not successful. Nevertheless, it has been claimed that the masking ability of the veneer restorations is highly dependent on the shade, translucency level and thickness of both the veneer materials and the resin cements used. This masking ability is further put into test when the underlying tooth substrate is darkly stained as in case of tetracycline stained teeth ${ }^{(19)}$.

In the current study, A1, or its equivalent in 3D mater shade guide (1M1), CAD-CAM specimens of three different categories (lithium disilicate glass ceramic, hybrid ceramic and zirconia reinforced glass ceramic), thicknesses $(0.7$ and $1.0 \mathrm{~mm})$ and translucency levels (high and low) were bonded to dark ceramic substrates using three different shades of resin cements (A1, white opaque and translucent). Thicknesses of $0.7 \mathrm{~mm}$ and $1.0 \mathrm{~mm}$ specimens were chosen for the study as these are the recommended higher veneer thickness when masking of the underlying tooth color is intended ${ }^{(20)}$. The color of final restoration was compared to a standard 1M1 3D master shade guide tab to evaluate their masking ability. A spectrophotometer has been used for color assessment as it allows for objective numerical expression of color parameters, standardization and $\operatorname{accuracy}^{(21)}$.

The null hypothesis that none of the veneer restorations tested will be able to mask the underlying stained base color was rejected. Both the hybrid ceramic and the lithium disilicate ceramic materials tested in in low translucency and in $1 \mathrm{~mm}$ and $0.7 \mathrm{~mm}$ thickness respectively could mask the underlying dark base and render restorations that very well match the desired $1 \mathrm{M} 1$ shade $\left(\left(\Delta \mathrm{E}^{*}\right.\right.$ values less than 3 ). On the other hand, all the zirconia reinforced glass ceramic material tested in both high and low translucencies and cemented with different resin cement shades rendered restorations that are clinically unacceptable in masking the underlying dark background (Delta $\mathrm{E}>20$ ). Those very high $\Delta \mathrm{E}^{*}$ values were mainly due to the lower $\mathrm{L}^{*}$ values, indicating darker restorations, and the inability of the restorations to hide the underlying dark color base. This may be attributed to the inherent higher translucency of zirconia-reinforced glass ceramics in comparison to lithium disilicate ceramics $^{(11,22,23)}$. Difference was attributed to the different grain size and crystalline structure of the materials. Hybrid ceramics on the other hand, were reported to have lower translucencies compared to other ceramics, which was attributed to their higher alumina content, allowing them to better mask the underlying base color ${ }^{(12)}$.

Notably, there is a lack of standardization in ceramic materials shades available in the market. Even though shade $\mathrm{A} 1$ or its corresponding $3 \mathrm{D}$ master shade 1M1 were chosen for all ceramics tested, their baseline color measured against a standard white background were significantly different (table 2). This may have added to the significant differences observed in the final restorations with the different ceramic materials tested. A similar observation depicting industrial standards inaccuracy was noted by CHANG et al.$^{(21)}$ in reference to resin cements.

In regards to veneer thickness, it has also been widely accepted that the greater the thickness of the ceramic restoration, the greater its opacity due to the diminished reflective effects of the underlying substrate $^{(24)}$ and, in the case of the current study, it would translate into it's a greater potential to mask the underlying dark base. This was demonstrated for most of the restorations tested (table 3), but the difference was not to a significant level (table 5). This may be due to the small difference in thickness between the ceramic specimens tested $(0.7 \mathrm{~mm}$ and 
$1 \mathrm{~mm}$ ) which did not have an important impact on the final restorations. Greater or smaller thicknesses $(>1 \mathrm{~mm}$ or $<0.7 \mathrm{~mm})$ may have rendered significant difference in the results as reported in several studies(25-27) but this would not be applicable for the current study which focuses on veneer restorations intended to mask underlying dark tooth substrates.

In contrast, the translucency level of the ceramic materials tested did on the other hand have a significant effect on the masking ability of the veneer restorations $(\mathrm{p}<0.001)$ with the low translucency specimens rendering restorations closer in color to the $1 \mathrm{M} 1$ shade. This suggest that the high translucency CAD-CAM ceramics of any composition should not be indicated for masking darkly stained teeth. The above findings necessitate the partial rejection of the second null hypothesis tested, as it was found that material composition and translucency level did affect the masking ability of the veneer while its thickness did not.

As demonstrated by previous studies, it has generally been accepted that resin cement shades have an important influence on the shade of the final veneer restoration, mainly due the reduced thickness of the restorations and hence their translucen$\mathrm{cy}^{(2,3,15,17)}$. This has been confirmed by the present study as there was a significant difference of the other surface of the ceramic specimens placed on the dark base with or without resin cementation. The ceramic surfaces after cementation were generally less red, less yellow yet less light as demonstrated by lower $\mathrm{a}, \mathrm{b}$ and $\mathrm{L}$ values respectively. The effect of the shade of the resin cement in the current study was nevertheless less evident with no significant difference noted between the different shades. Only when analyzed with interaction with other variables tested in the study did A1 resin cement shade have a significant effect on the shade of the final restoration in comparison to the $\mathrm{WO}$ and $\mathrm{T}$ shades. This finding requires the partial rejection of the third null hypothesis, as the shade of the resin cement was considered as an influential factor only in correlation with other factors pertaining to the overall clin- ical situation. This is in agreement with TuRGUT et al. ${ }^{(15)}$ who stated that "the color of a ceramic is influenced not only by the underlying substrate and ceramic thickness but also by the interactions between them". This interaction between several factors on the final color of the veneer restoration may be the reason for the wide controversy in the literature in regards to the effect of the resin cement shades on the final restoration ${ }^{(15,21,28,29)}$. In clinical, and due to lack of certainty in this regard, the dentist often resorts to the use of try-in pastes to better achieve the desired final shade of the restoration. Nevertheless, the shade observed with the try-in paste should be considered with caution, as a study by AlghAZALI et al. ${ }^{(30)}$ reports that significant color differences were found between the try-in pastes and the cured resin of the same shade.

\section{CONCLUSION}

Within the limitations of the current in-vitro study, the following conclusions could be made when attempting to mask tetracycline darkly stained teeth:

1. Veneer restorations made of lithium disilicate glass ceramic and hybrid ceramics having an inherent lower translucency have a better chance to mask darkly stained teeth compared to zirconia reinforced lithium silicate ceramics having a higher translucency.

2. High translucency ceramic materials are not recommended when masking of darkly stained teeth is desired.

3. Ceramic veneer thickness in the range of 0.7 $-1.0 \mathrm{~mm}$ does not affect the masking ability of the final veneer restoration.

4. Resin cements affects the shade of the final veneer restorations, but the extent of the effect of its shade is mostly appreciated in correlation with other factors pertaining to the clinical situation. 


\section{REFERENCES}

1. Afroz S, Rathi S, Rajput G, Rahman SA. Dental est het ics and its impact on psycho-social well-being and dental self confidence: a campus based survey of north Indian university students. J Indian Prosthodont Soc. 2013 Dec; 13(4):455-60.

2. CHU FCS. Clinical considerations in managing severe tooth discoloration with porcelain veneers. J Am Dent Assoc 1939. 2009 Apr; 140(4):442-6.

3. Jun SK, WiLSON S. Restoration of severely discolored maxillary anterior teeth with porcelain laminate veneers. Pract Proced Aesthetic Dent PPAD. 2008 Jun;20(5):285-7.

4. Chan DCN, Rozier GS, Steen A, Browning WD, MozafFARI MS. St andar dized met hod to produce tet racycl inestained human molar teeth in vitro. Quintessence Int Berl Ger 1985. 2006 Sep;37(8):637-46.

5. Driscoll MS, Rothe MJ, Abrahamian L, Grant-Kels JM. Long-term oral antibiotics for acne: is laboratory monitoring necessary? J Am Acad Dermatol. 1993 Apr;28(4):595-602.

6. SÁnchez AR, Rogers RS, SHERIdAn PJ. Tet r acycl ine and other tetracycline-derivative staining of the teeth and oral cavity. Int J Dermatol. 2004 Oct;43(10):709-15.

7. Krastl G, Allgayer N, Lenherr P, Filippi A, Taneja P, WeIger R. Tooth discoloration induced by endodont ic materials: a literature review. Dent Traumatol Off Publ Int Assoc Dent Traumatol. 2013 Feb;29(1):2-7.

8. Gracis S, Thompson VP, Ferencz JL, Silva NRFA, BonFANTE EA. A new classification system for all-ceramic and ceramic-like restorative materials. Int J Prosthodont. 2015 Jun;28(3):227-35.

9. Makarouna M, Ullmann K, Lazarek K, Boening KW. Six-year clinical performance of lithium disilicate fixed partial dentures. Int J Prosthodont. 2011 Jun;24(3): 204-6.

10. Gehrt M, Wolfart S, Rafai N, Reich S, Edelhoff D. Clinical results of lithium-disilicate crowns after up to 9 years of service. Clin Oral Investig. 2013 Jan;17(1): 275-84.

11. Elsaka SE, Elnaghy AM. Mechanical properties of zirconia reinforced lithium silicate glass-ceramic. Dent Mater Off Publ Acad Dent Mater. 2016;32(7):908-14.
12. Awad D, Stawarczyk B, Liebermann A, Ilie N. Translucency of esthetic dental restorative CAD/CAM materials and composite resins with respect to thickness and surface roughness. J Prosthet Dent. 2015 Jun;113(6): 534-40.

13. Krüger S, Deubener J, Ritzberger C, Höland W. Nucl eation Kinetics of Lithium Metasilicate in $\mathrm{ZrO} 2-B e a r i n g$ Lithium Disilicate Glasses for Dental Application. Int J Appl Glass Sci. 2013;4(1):9-19.

14. Preis V, Hahnel S, Behr M, Bein L, Rosentritt M. Invitro fatigue and fracture testing of CAD/CAM-materials in implant-supported molar crowns. Dent Mater Off Publ Acad Dent Mater. 2017;33(4):427-33.

15. Turgut S, Bagis B. Effect of resin cement and ceramic thickness on final color of laminate veneers: an in vitro study. J Prosthet Dent. 2013 Mar;109(3):179-86.

16. Ruan D, Qian C, Zhang X, Bian Y, Yu Y, Yu W. [Clinical analysis of colour distribution in tetracycline teeth]. Shanghai Kou Qiang Yi Xue Shanghai J Stomatol. 2006 Dec;15(6):567-70.

17. Turgut $S$, B Agis B. Col our stabil it y of l a minate veneer s: an in vitro study. J Dent. 2011 Dec;39 Suppl 3:e57-64.

18. Ghinea R, Pérez MM, Herrera LJ, Rivas MJ, Yebra A, Paravina RD. Color difference threshol ds in dental ceramics. J Dent. 2010;38 Suppl 2:e57-64.

19. Chaiyabutr Y, Kois JC, Lebeau D, Nunokawa G. Effect of abutment tooth color, cement color, and ceramic thickness on the resulting optical color of a CAD/CAM glass-ceramic lithium disilicate-reinforced crown. J Prosthet Dent. 2011 Feb;105(2):83-90.

20. Chu FCS, Sham ASK, Luk HWK, Andersson B, Chai J, CHow TW. Thr eshold cont rast $r$ at io and masking abil it $y$ of porcelain veneers with high-density alumina cores. Int J Prosthodont. 2004 Feb;17(1):24-8.

21. Chang J, Da Silva JD, Sakai M, Kristiansen J, IshikawaNAGaI S. The optical effect of composite lut ing cement on all ceramic crowns. J Dent. 2009 Dec;37(12):937-43.

22. Kanchanavasita W, Triwatana P, Suputtamongkol K, Thanapitak A, Chatchaiganan M. Contrast $r$ at io of six zirconia-based dental ceramics. J Prosthodont Off J Am Coll Prosthodont. 2014 Aug;23(6):456-61.

23. SEN N, Us YO. Mechanical and optical properties of monolithic CAD-CAM restorative materials. J Prosthet Dent. 2018 Apr;119(4):593-9. 
24. Vichi A, Ferrari M, DaVidson CL. Influence of cer amic and cement thickness on the masking of various types of opaque posts. J Prosthet Dent. 2000 Apr;83(4):412-7.

25. Czigola A, Abram E, Kovacs ZI, Marton K, Hermann P, Borbely J. Effects of substrate, ceramic thickness, translucency, and cement shade on the color of CAD/ CAM lithium-disilicate crowns. J Esthet Restor Dent Off Publ Am Acad Esthet Dent Al. 2019 Sep;31(5):457-64.

26. Passos L, Linke B, Street A, Torrealba Y. Effect of thickness, translucency, and firing protocol on the masking ability of a CAD/CAM zirconia-reinforced lithium silicate for different backgrounds. Int J Comput Dent. 2019;22(1):29-38.

27. Gunal B, Ulusoy MM. Opt ical properties of contemporary monolithic CAD-CAM restorative materials at different thicknesses. J Esthet Restor Dent Off Publ Am Acad Esthet Dent Al. 2018;30(5):434-41.

28. Azer SS, Ayash GM, Johnston WM, Khalil MF, RosenSTIEL SF. Effect of est het ic core shades on the final color of IPS Empress all-ceramic crowns. J Prosthet Dent. 2006 Dec;96(6):397-401.

29. KaraAgaclioglu L, Yilmaz B. Influence of cement shade and water storage on the final color of leucite-reinforced ceramics. Oper Dent. 2008 Aug;33(4):386-91.

30. Alghazali N, Laukner J, Burnside G, Jarad FD, Smith PW, Preston AJ. An invest igat ion int o the effect of tryin pastes, uncured and cured resin cements on the overall color of ceramic veneer restorations: an in vitro study. $\mathrm{J}$ Dent. 2010;38 Suppl 2:e78-86. 